\title{
UNA LECTURA DEL MOVIMIENTO POR LA EDUCACIÓN EN CHILE (2011-2013) A PARTIR DE LA PRODUCCIÓN DE GRAFITIS LINGÜÍSTICOS
}

\author{
REBECCA LÓPEZ MORALES* \\ CAMILA CÁRDENAS NEIRA ${ }^{* *}$
}

\begin{abstract}
RESUMEN
Este artículo analiza discursos de protesta callejera en forma de grafitis linguiísticos producidos en el marco del Movimiento por la Educación en Chile (2011-2013), con el objetivo de reconocer sus propósitos y estrategias comunicativas sistemáticas, así como sus usos y alcances sociopolíticos predominantes. Desde la perspectiva de los Estudios Críticos del Discurso (ECD), se examinan veinticinco grafitis producidos en las ciudades de Santiago y Valdivia, indagando específicamente en la conformación de ideologías e identidades juveniles. Se concluye que los/as estudiantes, apropiándose del espacio público, subvierten los significados hegemónicos para ampliar el campo del conocimiento social con otras representaciones relativas al conflicto educativo. De este modo, los grafitis analizados constituyen contradiscursos que redefinen la relación entre acción juvenil y educación, a partir de la polarización, la crítica y la reivindicación de sus ideales, actos y demandas colectivas.

PALABRAS CLAVE: MOVIMIENTO ESTUDIANTIL CHILENO, GRAFITI, DISCURSOS JUVENILES

* Estudiante del Magíster en Comunicación de la Universidad Austral de Valdivia, Chile. E-Mail: pichimalen.lm@gmail.com.

** Doctora en Traducción y Ciencias del Lenguaje y miembro del Grupo de Estudios del Discurso (GED) de la Universitat Pompeu Fabra, Barcelona, España. E-Mail: camila.cardenas.neira@gmail.com.
\end{abstract}




\title{
UMA LEITURA DO MOBILIZAÇÃO ESTUDANTIL PELA EDUCAÇÃO NO CHILE (2011-2013) A PARTIR DA PRODUÇÃO DE GRAFITES LINGUÍSTICOS
}

\begin{abstract}
RESUMO
Este artigo analisa os discursos de protestos na rua na forma de grafites linguísticos durante a Mobilização estudantil pela Educação no Chile (2011-2013), com o objetivo de reconhecer seus objetivos e estratégias comunicativas sistemáticas, assim como seus usos e alcances sócio-políticos predominantes. Da perspectiva dos Estudos Críticos do Discurso (ECD), são examinados 25 grafites realizados nas cidades de Santiago e Valdivia, indagando especificamente na conformação de ideologias e identidades dos jovens. É possível concluir que os/as estudantes, através da apropriação do espaço público, subvertem os significados hegemônicos para ampliar a área do conhecimento social com outras formas de representações relacionadas com o conflito educativo. Desta forma, os grafites analisados constituem contradiscursos que redefinem a relação entre ação juvenil e educação, a partir da polarização, a crítica e a reivindicação de seus ideais, ações e exigências coletivas.
\end{abstract}

\section{PALAVRAS CHAVE: MOVIMENTO ESTUDANTIL CHILENO, GRAFITE, DISCURSOS JUVENIS}

\section{A READING OF THE STUDENT MOVEMENT FOR EDUCATION IN CHILE (2011-2013) FROM THE PRODUCTION OF LINGUISTIC GRAFFITI}

\begin{abstract}
The present article aims at recognizing the purposes and systematic communication strategies as well as their prominent uses and socio-political achievements of linguistic graffiti, by means of an analysis of street protest discourses (linguistic graffiti) produced in the context of the Student Movement for Education in Chile (2011-2013). From the perspective of Critical Discourse Studies (CDS), 25 graffiti produced in the cities of Santiago and Valdivia are thoroughly examined, focusing on the shaping of youth identities and ideologies. We conclude that the appropriation of public spaces is instrumental for male and female students to subvert hegemonic meanings and expand the field of social knowledge with other representations related to the educational conflict. The analyzed graffiti, therefore, constitute counterdiscourses redefining the relationship between youth action and education from the polarization, criticism and claim of students' ideals, actions, and collective demands.
\end{abstract}

KEY WORDS: CHILEAN STUDENT MOVEMENT, GRAFFITI, YOUTH DISCOURSES 


\section{INTRODUCCIÓN}

En esta investigación abordamos el grafiti lingüístico como práctica comunicativa y como práctica social. En cuanto práctica comunicativa, comporta diversos niveles de significación que convergen en su producción — sentidos globales y locales, presuposiciones o implícitos-, involucra diversas relaciones con el contexto - participantes, acciones y posicionamientos-, e implica distintas modalidades semióticas - tipología, color, tamaño, disposición-, entre otras características. En cuanto práctica social, da cuenta de finalidades políticas, conocimientos y memorias comunes, preferencias ideológicas e identidades compartidas.

Ambas dimensiones del grafiti se actualizan a partir de un contexto específico: Chile postdictadura (1991-2015), específicamente durante el gobierno de la coalición de derecha representado en la figura de Sebastián Piñera (2010-2014). El escenario se configura por la coyuntura del Movimiento por la Educación (2011-2013), en el que diversos actores sociales se han alineado con la construcción de un discurso de rechazo a la educación neoliberal (Cabalin, 2014, 2012). A raíz de la problemática educativa, el descontento ciudadano se ha proyectado a otros sectores, surgiendo múltiples reivindicaciones que evidencian la crisis del sistema social atravesado por el lucro y la mercantilización (Cárdenas, 2013). Tales reivindicaciones se han dado a conocer a través de diversas manifestaciones como protestas, marchas, asambleas, tomas de establecimientos, etcétera, las que han generado un sinnúmero de expresiones contestatarias, en su gran mayoría de intención artística (López, 2014).

En este escenario, la producción de grafitis linguísticos se acrecienta cuando el conflicto subsiste sin que las demandas sean públicamente reconocidas y escuchadas. De hecho, la protesta se realiza cuando existe una queja que necesariamente debe ser emplazada y hacerse visible. El contexto de las movilizaciones constituye, entonces, un momento crítico para la aparición de grafitis en las calles, puesto que estos representan una ruptura con la norma establecida y, por ende, una manera de confrontar los discursos oficiales. Este carácter oficial proviene fundamentalmente de los discursos que se mantienen en los medios de comunicación tradicionales (Escamilla, 2013), los que al responder a los intereses de los poderes económicos y políticos parcializan, tergiversan o manipulan la información, deslegitimando a los actores que interpelan las demandas sociales. 
Dicho esto, escogemos estudiar el grafiti lingüístico como discurso de resistencia - o contradiscurso - por dos razones principales: primero, para echar luz sobre un objeto escasamente investigado desde una perspectiva comunicativa, muchas veces soslayado por su aparente marginalidad; segundo, para conectar estas expresiones juveniles a un movimiento social en curso, signado por los conflictos de poder que encubren dinámicas de desigualdad y segregación que resultan cada vez más insostenibles dentro de la sociedad chilena.

En este sentido, el estudio busca responder las siguientes interrogantes: ¿cómo y para qué funcionan los grafitis lingüísticos producidos en el contexto de movilizaciones estudiantiles?, ¿qué propósitos comunicativos persiguen y cuáles son sus principales características discursivas?, ¿cuáles son los sistemas de creencias representadas en estos discursos y qué actores sociales se ven confrontados? En virtud de estas preguntas, nos proponemos satisfacer tres objetivos centrales:

- Identificar los propósitos socio-comunicativos que caracterizan al grafiti lingüístico como contradiscurso emergente;

- Describir las estrategias lingüístico-discursivas que son definidoras de los grafitis producidos en este contexto de movilizaciones, y;

- Explicar sus alcances socio-políticos en la conformación de ideologías e identidades grupales que modelan la acción juvenil.

En primer lugar, se delinean los aportes teóricos con el propósito de establecer: a) una revisión focalizada en las nociones de juventud y política, lo que permite comprender la gestación de los ciclos movilizatorios estudiantiles; b) una aproximación socio-histórica a la producción de escrituras expuestas en Chile, en relación con las distintas coyunturas que las visibilizan en el pasado reciente, y; c) una aproximación comunicativa a la creación de grafitis por parte de los/as jóvenes, en el marco del conflicto educativo que circunscribe sus procesos de construcción y recepción. En segundo lugar, se caracterizan los pasos metodológicos y se exponen las categorías de análisis adecuadas al género discursivo explorado, para luego organizar los resultados obtenidos a partir de sus relaciones temáticas más prominentes. En tercer lugar, se propone una síntesis que conecta los alcances teóricometodológicos relevados con las reflexiones derivadas del análisis del corpus. 


\section{PRÁCTICAS JUVENILES. VISIBILIZACIÓN Y RESISTENCIA}

\section{a) Emergencia histórica: la construcción de lo juvenil en Chile}

Para atender la presencia de los actores juveniles en la historia contemporánea del país es necesario prestar atención a dos procesos articulados a lo largo del siglo XX. Por un lado, las transformaciones económicas, políticas y culturales que otorgan ciertas condiciones estructurales para que estos sujetos experimenten de manera diferenciada el tránsito de la niñez a la adultez (Cárdenas, 2011a) y, por otro lado, el impacto que dichas condiciones tienen en la configuración de la juventud como objeto de investigación para las Ciencias Sociales (Aguilera, 2009). A partir de estas trayectorias, se vuelven operativas ciertas nociones como las de moratoria social y crédito vital (Balardini, 2000; Reguillo, 2000; Margulis y Urresti, 1996), las cuales hacen posible distinguir analíticamente el ser joven como categoría de estudio en virtud de contextos espaciales y temporales particulares.

En lo que respecta al caso chileno, durante la primera mitad del siglo XX se genera «la convergencia entre vanguardias estéticas de una aristocracia rebelde... y las vanguardias político-sociales de capas medias y organizaciones obreras y militares» (González, 2002:62). De allí que la matriz «mesocrática-ilustrada-masculina» (González, 2002:89) sea la que configura en sus orígenes el prototipo identitario juvenil chileno. En la segunda mitad del siglo XX, especialmente entre las décadas del 50 y del 60, se conjugan dos trayectorias de interés: la constitución de las primeras culturas juveniles (González, 2011), de un lado, y la conformación de las primeras culturas revolucionarias (González, 2010), de otro lado.

Las primeras surgen en virtud de un contexto marcado por la paulatina modernización de la esfera material que, sustentada en gran medida por un estado desarrollista y populista, posibilita la urbanización, la expansión de la matrícula educativa, la industrialización y la migración campo-ciudad. Estos avances facilitan la extensión de la condición juvenil a hombres y mujeres de capas medias y bajas, quienes pueden acceder a diversos bienes simbólicos y actividades focales que organizan espacios propios de socialización, ocio y entretenimiento. Las segundas están marcadas fundamentalmente por los procesos de reforma universitaria, desde sus inicios en 1967 hasta los primeros años de 1970. De acuerdo a González, «son los grupos secularizados discursiva y empíricamente de las instituciones educativas los que 
sintetizan una alteración en las trayectorias de las identidades juveniles, [las] que son capaces... de pasar fugaz o sistemáticamente de las reivindicaciones del co-gobierno universitario a la destrucción o toma del poder; de la rabia sectorial a la «revuelta popular»» (González, 2010:118).

En este contexto se desarrolla una activa participación de los/as jóvenes militantes en el advenimiento del Gobierno de Salvador Allende, donde destaca una fuerte ligazón política de parte de estudiantes, obreros y pobladores en el fortalecimiento del proyecto socialista de la Unidad Popular (UP). La obra Viaje por la juventud (Abarca y Forch, 1972) da cuenta de la articulación juvenil de la época, demostrando cómo esta sensibilización por las transformaciones políticas adquiere un carácter transversal a hombres y mujeres, jóvenes escolarizados de capas medias y altas, jóvenes del proletariado, jóvenes de comunidades indígenas, entre otros.

No obstante, la asunción democrática del proyecto de la UP es rápida y brutalmente interrumpida por el golpe de estado de 1973 perpetrado por las fuerzas armadas, quienes instauran una de las dictaduras más sangrientas y duraderas de América Latina. Con el terrorismo de estado (Calveiro, 2008; Obando, 2008) se institucionalizan las prácticas de detención, secuestro, tortura y desaparición forzada, las que, de acuerdo a Salazar y Pinto (1999), tuvieron entre sus principales víctimas a los/as jóvenes militantes de la época. Por ello, los primeros años de la dictadura obligaron el repliegue de la acción política, en general, y de la acción política juvenil, en particular, si bien sus prácticas de asociatividad no llegaron a desintegrarse del todo.

Entre los años 1983 y 1987 se producen las mayores jornadas de lucha en contra de la dictadura de Augusto Pinochet (Salazar, 2006). En estos años se reconfigura el espacio de acción política juvenil mediante el trabajo comunitario, buena parte en las periferias, y la contención callejera en barrios y centros urbanos. Así, ambos ejes de actuación devienen en un proceso mayor de reflexión personal y colectiva que busca poner en jaque la mantención del régimen militar. Los/as jóvenes, junto con rearticular redes de apoyo eficaces con los sectores populares, establecen dispositivos mediáticos para transversalizar sus reivindicaciones a la ciudadanía. Todas estas acciones confirman la recomposición de las bases juveniles, quienes asumen públicamente demandas colectivas y salen progresivamente del anonimato y la clandestinidad. 
Según Aguilera (2009), es precisamente en los años 80 donde se observa una preocupación sistemática por la juventud como actor social específico, que requiere y merece la atención de las Ciencias Sociales. Es precisamente en el contexto de dictadura donde se desarrolla y consolida significativamente la investigación sobre los/as jóvenes, periodo en que se publica una obra clave para su constitución: Juventud chilena. Razones y subversiones (Agurto, Canales y De la Maza, 1985). En ella se reconocen dos lecturas teóricas que permanecerán en las décadas siguientes (Aguilera, 2009): a) una fuerte crítica al concepto de anomia (Valenzuela, 1984), y b) una línea de interpretación de la juventud y sus acciones a partir de las categorías de movimiento social emergente y movimiento juvenil popular.

En lo sucesivo, los principales ejes temáticos que predominan en los estudios sobre juventud hasta principios de los 2000 dicen relación con: a) la perspectiva de joven dañado: que atiende a los individuos con problemas de integración social producto de accidentes biográficos en sus trayectorias vitales; b) la propuesta de conversación juvenil: que busca construir sentidos sobre las experiencias juveniles a partir de distintas voces que pongan en diálogo vivencias comunes; c) las nociones de sociabilidad y socialidad juvenil: donde se ubican los estudios de las modalidades de estar juntos que son construidas desde la espectacularidad mediática, y; d) la visión de violencia juvenil: que remite a los procesos de conflictividad en sectores populares y espacios escolares (Aguilera, 2009).

Una de las características que aglutina dichos ejes es la pérdida de agencia de los sujetos juveniles (Cárdenas, 2011a), quienes pasan a ser concebidos como un problema - a conjurar/controlar- (Agurto, Canales y De la Maza, 1985) sobre el cual hay que aplicar soluciones eficientes. Por esta razón, el estado chileno ejecuta durante los 90 un proyecto asistencialista que busca dar a los/as jóvenes seguridades en áreas como la educación y el trabajo, acotando su acción al ámbito individual y familiar. Detrás de estos esfuerzos normativos pervive una actitud altamente paternalista que resalta la inmadurez juvenil y su condición inacabada como sujetos sociales funcionales, argumento que, sostenidamente expuesto a la opinión pública, termina negándolos como sujetos totales (Aguilera, 2012; Chaves, 2005).

No obstante, el siglo XXI trae consigo el advenimiento de nuevas generaciones, fenómeno que, a su vez, posibilita la renovación de los sentidos asociados al cambio histórico. De esta manera, las dislocaciones traumáticas del pasado reciente, así como las lecturas que par- 
cializan, neutralizan y naturalizan la acción juvenil signada por estos quiebres, pueden resignificarse en las articulaciones sociales, culturales y políticas que el reemplazo generacional cristaliza, habilitando universos simbólicos alternativos (Achugar, 2006) desde los cuales redimensionar los imperativos y las promesas de la época. De esta forma, el tránsito de la dictadura a la democracia puede sintetizarse como una oportunidad de transformación positiva, toda vez que potencia lecturas alternativas de la realidad y otros referentes de participación social futura. Es en este contexto donde ubicamos los ciclos de movilización estudiantil de postransición.

\section{b) Trayectoria política: el movimiento estudiantil chileno de postdictadura}

Durante el periodo transicional se estabiliza la percepción de una juventud que no está ni ahí con la política (Muñoz, 2011, 2004), representación que resulta funcional a los propósitos de las clases dirigentes de resguardar el orden y reducir la polarización social. En esta dirección, son numerosos los estudios que constatan una supuesta apatía juvenil sobre la base de dos indicadores centrales: la inscripción en los registros electorales y la militancia en partidos políticos (Cárdenas, 2011a). Sobre la base de esta comprensión instrumentalizada de la política se establecen relatos mitológicos (Aguilera, 2014) sobre los/as jóvenes «comprometidos» de los años 70 y 80 , y los/as jóvenes «descomprometidos» de hoy (1990-2010) (Millán, 2010). A partir de estas presunciones, se asume que la «conciencia colectiva» de las generaciones anteriores habría devenido en «el individualismo» de las generaciones posteriores.

No obstante, ser «joven participante» no es una identidad única e inamovible que emerja desapegada de los contextos históricos, económicos y culturales donde se resignifica la experiencia política, por lo que la desafección hacia los procesos eleccionarios y la afiliación partidista debe leerse, necesariamente, como una de las consecuencias palpables de la dictadura en los/as ciudadanos/as más jóvenes. Además, es imposible reducir la participación política a la política institucionalizada, si bien se constituye en una de las principales imposiciones con las cuales las sociedades adultocéntricas (Duarte, 2012) estructuran los deberes y derechos juveniles.

En este sentido, la apatía juvenil puede interpretarse más bien como una crítica al sistema democrático estrenado en la transición y que, con el pasar de los años, se traduce en una profunda desconfianza 
en las instituciones políticas y en la representatividad de los partidos y sus miembros (Sandoval, 2012). Esto explica que, progresivamente, los contenidos simbólicos asociados con el vínculo política-juventud hayan ido sometiéndose a objeciones y revisiones más sistemáticas. Si bien es cierto que se produce un proceso más amplio de desmovilización social y política entre 1990 y 1999 (Aguilera, 2012), esto no implica, necesariamente, una pérdida de los sentidos políticos sino, más bien, su redefinición.

Se trata, por tanto, de un cambio generacional en los modos de concebir y ejercer la política, supeditado a un proceso más general de subjetivación de las interacciones sociales (Aguilera, 2010). Esto se traduciría, a su vez, en la renovación de las prácticas políticas juveniles, las cuales, de acuerdo a Baeza y Sandoval (2009), se caracterizan actualmente por: a) la horizontalidad de la acción que incluye diversas formas de asambleísmo y vocerías no jerárquicas; b) emplazar lo cultural como campo de construcción de lo político en la cotidianidad; c) la lógica de acción directa sin intermediación partidista; d) la primacía del trabajo de base mediante la representación de los colectivos; e) el trabajo en red, cada vez más soportado tecnológicamente; f) el respeto por las diferencias y la constitución dialógica del debate político, y; g) la autogestión y la autoformación sin dependencia de entidades externas.

Las movilizaciones estudiantiles que comienzan a gestarse a partir de los años 2000 se emplazan en un contexto de amplio malestar producto de los profundos abusos y desigualdades (Mayol y Azócar, 2011), que tienen su origen en el modelo neoliberal instaurado en dictadura y consolidado desde el retorno a la democracia (Bellei, Cabalin y Orellana, 2014; Bellei y Cabalin, 2013; Cabalin, 2014, 2012; Salinas y Fraser, 2012; Somma, 2012; Oliva, 2010, 2008; Torche, 2005a, 2005b). Dicho modelo ha generado una inmensa concentración de la riqueza, obligando el endeudamiento y la precarización de las capas medias y bajas, las cuales no han sido realmente incluidas en un proyecto de desarrollo justo y digno. Es así como las expectativas incumplidas de integración y movilidad social empiezan a ser progresivamente sindicadas por los/as jóvenes (Sandoval, 2012), quienes identifican en la educación su expresión más palpable.

En efecto, el sistema educacional chileno fue adecuado al modelo de sociedad capitalista, autoritario en lo político-cultural y organizado en torno al individualismo y el mercado en lo económico-social (Garretón et al., 2011). De acuerdo a Latorre (2013), los/as jóvenes no solo encarnan la manifestación del fracaso de la modernización neoli- 
beral de la educación, sino que plantean una impugnación global a dicho modelo y a la estructura institucional que lo sostiene.

En este escenario, los gobiernos de la Concertación (1990-2010) se concentraron en mejoras cuantitativas del modelo (acceso, cobertura y equipamiento), pero no así en mejoras cualitativas que impugnaran el estatuto de la educación como bien de consumo. A partir de los llamados «mochilazos» protagonizados en 2001 por estudiantes de la Región Metropolitana, se reconfiguran en Chile unos repertorios de acción juvenil que ya habían tenido lugar en dictadura, esto es, transitar de peticiones locales - becas de alimentación y transporte, gratuidad en la Prueba de Selección Universitaria, término de la Jornada Escolar Completa, entre otras- a demandas globales, lo que en el año 2006 desemboca en las movilizaciones estudiantiles que consiguen la derogación de la Ley Orgánica Constitucional de Enseñanza (LOCE) y la instauración de una nueva Ley General de Educación (LGE).

Este ciclo de movilización estudiantil, conocido como Revolución Pinguiina, se caracteriza por ser el más masivo desde la transición democrática (Domedel y Peña y Lillo, 2008), y se conforma principalmente por estudiantes secundarios/as de establecimientos municipales del país. Se constituye así un nuevo o novísimo movimiento social (Cárdenas, 2011b), con probada densidad organizacional, territorial y temporal (Garretón et al., 2011). Sus repertorios de acción configurados por claras estrategias de protesta y visibilización pública, ocupaciones, asambleas y jornadas de reflexión, devienen en la conformación de un Bloque Social por la Educación, con participación de padres y apoderados, docentes, co-docentes, estudiantes universitarios y técnicos (Cárdenas, 2011b), marcando con ello una forma inédita de articulación política.

A pesar de que las reformas políticas del periodo no resuelven las demandas estructurales, la Revolución Pingüina instala en la sociedad chilena de postdictadura una coyuntura inédita de debate público en torno a las necesidades de transformación educativa (Cabalin, 2014, 2012), mediante el desvelamiento de las lógicas de segregación que regulan el acceso a derechos sociales básicos de acuerdo a la capacidad de pago de las familias. En efecto, este ciclo movilizatorio consigue proponer una sólida base de discusión ideológica sobre dos aspectos centrales (Bellei y Cabalin, 2013): a) logra formular una demanda de igualdad de oportunidades cuya reivindicación central es la concepción de una educación de calidad como derecho universal garantizado, y; b) logra identificar fundamentos específicos del mercado de la 
educación, cuyo desmantelamiento es ampliamente aceptado por la ciudadanía, de allí que estas movilizaciones se caracterizaran por alcanzar una gran aprobación y repercusión social.

Cinco años más tarde, en abril de 2011, la mayoría de los/as jóvenes que participaron de la Revolución Pingüina se hacen parte de un ciclo movilizatorio mucho más extenso, en el que los/as estudiantes universitarios/as son los/as principales protagonistas. En esta ocasión, el movimiento estudiantil se enfrenta al gobierno de derecha encabezado por el empresario Sebastián Piñera (2010-2014). Al inicio de las protestas, la principal demanda se orienta a criticar los altos costos de los estudios superiores, y los créditos bancarios usureros que las familias deben pagar para garantizar el acceso de sus hijos/as a una carrera profesional. No obstante, tal y como ocurre en 2006, rápidamente las peticiones locales devienen en demandas globales, las que se concentran en una única consigna general: «educación gratuita y de calidad para todos/as».

A corto andar, las protestas se acrecientan y se sostienen hasta por siete meses consecutivos, extendiéndose hasta hoy (2015) con sucesivos focos de visibilización. Se pliegan los estudiantes secundarios y los universitarios de corporaciones privadas, así como otros actores estratégicos tales como docentes y trabajadores, aumenta la aprobación ciudadana —en torno al 80\% según sondeos del período, y aumenta también la desaprobación del gobierno — que llega a bordear apenas el 20\% de aceptación-.

En este escenario, se profundizan y perfeccionan muchas de las dinámicas de participación política basadas en el asambleísmo, el trabajo de bases y la articulación de las diversas orgánicas estudiantiles, al tiempo que se robustecen las estrategias de contención e información que trazan una convergencia inédita entre los espacios de protesta offline y online, las cuales resultan esenciales para emplazar un discurso unificado de rechazo al paradigma neoliberal (Cárdenas, 2014b).

En consecuencia, es indudable que estas movilizaciones sitúan a las generaciones juveniles como actores sociales fundamentales dentro los actuales debates educativos, pues desempeñan un rol histórico en la re-politización de lo público (Cárdenas, 2014b; Latorre, 2013) —un reencantamiento, como sugieren Portillo et al., (2012)—. Dicha repolitización se relaciona con «la operación productora de una opción de disidencia, de la construcción de discursos contrahegemónicos... [que modifican] el escenario valorativo... de la sociedad» (Mayol y 
Azócar, 2011:3). En efecto, esta insurgencia discursiva (Pino-Ojeda, 2014) ejercida por los/as estudiantes ha tratado de refundar el sentido común de las personas, y de reorientar la discusión política con otros marcos de comprensión (Cárdenas, 2014b), pues ayuda a «nombrar lo que hasta ayer era innombrable» (Garcés, 2013:89), y provoca la apertura a «formas de conciencia antes desconocidas» (Mayol y Azócar, 2011:10). Es en esta dirección que nos aproximamos al estudio de los grafitis linguísticos, con el fin de analizar cuáles son los significados que los/as jóvenes construyen en este contexto de transformaciones sociopolíticas y sociocognitivas.

\section{EL GRAFITI COMO PRÁCTICA SOCIAL}

\section{a) Delimitación conceptual}

Comunicarse corresponde a una acción inherente al ser humano, quien posee la necesidad de configurar su entorno y relacionarse con otros valiéndose de distintas materialidades. Cualquiera sea la modalidad de expresión adoptada, ésta queda supeditada al ámbito del pensamiento. Para Silva (1987), el pensamiento mantiene, dentro de nuestra tradición cultural, una dependencia dicotómica con la acción. En efecto, expresión y acción corresponden a campos bien distintos: mientras la primera atiende a la representación de conceptos por medio de signos convencionales, la segunda define el movimiento sobre el mundo, bien de un cuerpo o de una fuerza. Pero el grafiti, como expresión y acción, es una de las prácticas humanas en que pensamiento y movimiento se fusionan.

Conforme pasa el tiempo es cada vez más común circular por las ciudades y encontrar en ellas rayados y pintadas, hasta el punto de pasar desapercibidas por los/as transeúntes que las han incorporado como parte de su cotidianidad. Por lo tanto, es evidente que «el mundo ha estado siempre plagado de inscripciones individuales, lanzadas a la atención de anónimos espectadores, como gritos desesperados contra la indiferencia y el olvido» (Ramírez, 1992:197-198). Por ello, el grafiti no corresponde solo a una de las formas de expresión más populares, adoptadas mayoritariamente por los/as jóvenes, sino también a una de las más históricas y naturales que el ser humano ha llevado a cabo en la búsqueda de medios por los cuales comunicarse. En la actualidad, esta práctica se ha masificado a tal punto de redefinir el espacio público y las maneras en que interactuamos con él, especialmen- 
te en contextos donde los conflictos sociales modifican los paisajes lingüísticos (Martín Rojo, 2013).

Estudiar el grafiti nos obliga a profundizar en cuestiones que van desde su raíz etimológica, pasando por antecedentes socio-históricos, hasta llegar a clasificaciones que puedan hacerse según diversas variantes o características que lo conforman. De allí que sea importante aclarar, en primera instancia, que la palabra grafiti corresponde a una adaptación al español de la palabra italiana graffitti. A su vez, ésta corresponde al plural de graffitto, que significa 'dibujo esgrafiado sobre la pared'. Todo parece indicar que, hoy por hoy, «el término adquiere un matiz de acción urbana mientras también subsiste un desplazamiento de 'medio' a 'objeto representado', para indicar una clase de mensajes consignados sobre los muros de las ciudades o sobre diferentes objetos del inventario citadino» (Silva, 1987:21, cursiva en el original).

El grafiti se puede definir de manera general como cualquier mensaje verbal o icónico realizado clandestinamente sobre alguna superficie - sea esta pública o privada - que asegure su difusión masiva en el paisaje cotidiano (Paredes, 2007). De acuerdo con ello, el grafiti implica tanto una práctica social - de irrupción anónima en el espacio - como comunicativa — apela a la reflexión y a la acción(Blume, 1999). Si bien se reconoce la complejidad que implica definir un discurso multiforme y dinámico, cuya situación de producción difícilmente puede reconstruirse con precisión, se ha generado consenso respecto de algunas de sus características principales.

Primero, sobresale su carácter escrito o gráfico, lo que nos indica, en resumidas cuentas, que significa a partir de su visualidad; segundo, la superficie en la cual se plasma debe asegurar su masificación, con lo que entendemos que el grafiti se emplaza en lugares estratégicos para que una gran cantidad de personas pueda observarlo, y; tercero, destaca el carácter ilegal que supone la clandestinidad de la acción. De acuerdo a Silva (1987), el denominador común de estas expresiones es su condición de escritura de lo prohibido, es decir, que se trata de un tipo de comunicación subversiva de órdenes ideológicos.

Esto explica por qué razón predomina una comprensión sesgada del grafiti como acto delictivo, difícilmente tolerado y sancionado socialmente (Blume, 1999), en ocasiones también perseguido y penalizado. En este sentido, Ramírez puntualiza que los grafitis constituyen «mensajes 'no institucionales', emitidos de espaldas al poder económico, político o cultural ... En este sentido revelan bien la cara 
oculta del sistema apareciendo ante nosotros como una contrafigura del establishment» (1992:198). Este carácter no institucional da cuenta de una necesidad de expresión latente de los actores sociales que llevan a cabo esta práctica. Si bien muchos de estos mensajes dan cuenta de reflexiones individuales, mayoritariamente encarnan experiencias y opiniones colectivas, principalmente de tipo político (Blume, 1999).

En esta línea, Silva caracteriza su producción en cuanto «explosión expresiva y comunicativa y como propuesta contrainformativa» (1987:22). Tal como ha confirmado Escamilla (2013), los grafitis desafían las lógicas hegemónicas que controlan la producción de contenidos noticiosos, de manera tal de demostrar cómo los medios de comunicación oficiales ocultan o falsean deliberadamente los conocimientos que resultan esenciales para comprender la vida en sociedad, sobre todo en contextos marcados por conflictos de poder.

En síntesis, el grafiti puede ser comprendido como una práctica socio-comunicativa que constituye contrapoder y contrahegemonía. Como se verá a continuación, su producción está fuertemente relacionada con situaciones históricas que incentivan la expresión popular, cuya manifestación de mensajes disidentes cuestiona algún aspecto de la realidad compartida.

\section{b) Delimitación histórica}

i) Escrituras expuestas en el pasado reciente chileno

Una de las manifestaciones más significativas de esta práctica aparece ligada a un incidente concreto: la exposición de un lienzo el 11 de agosto de 1967 con la frase «Chileno: El Mercurio miente». Este mensaje fue desplegado en el frontis de la Pontificia Universidad Católica en Santiago, en una toma realizada por los/as estudiantes como forma de presión a sus demandas. De acuerdo a Araya, «la frase se hizo inmediatamente famosa... fue un llamado de atención a la sociedad para decirle que la reforma universitaria seguía en pie, aunque se la desacreditara por medio de columnas y calumnias» (2008:159). Lo que el diario de derecha buscó fue difamar la acción estudiantil en el marco de una lucha legítima. Los/as jóvenes mostraron estratégicamente esta manipulación, inscribiendo una advertencia notable en la conciencia colectiva.

Este hecho es relevante no solo porque constituye un antecedente valioso de escrituras expuestas en Chile (Araya, 2008), sino además porque encarna, en toda su amplitud, el carácter performativo del len- 
guaje: no solo expresó algo, sino que hizo algo al mismo tiempo; protestó y resistió los embates de las élites político-mediáticas. En cuanto discurso contestatario, expuso a la vista de los/as transeúntes que estos mensajes son portadores de una historia que llaman a reconstruir. Según Araya: «este acontecimiento de escritura no se inserta únicamente en la historia del movimiento estudiantil ni de la historia política de Chile: se inscribe también en una historia contemporánea de los usos contestatarios de la escritura y aquí, más específicamente, se articula a una verdadera estrategia colectiva de resistencia política» (2008:160).

Es importante señalar que los/as estudiantes chilenos expresaron mensajes de esta índole mucho antes del mayo del 67. Araya (2008) señala que en 1926, a propósito de las reformas universitarias de ese año, los/as jóvenes se tomaron la Universidad de Chile y desplegaron un lienzo con la palabra LIBERTAD. El acontecimiento de «El Mercurio», sin embargo, tiene la particularidad de cuestionar explícitamente a uno de los poderes hegemónicos del país. Así, su discurso «guarda, además, la espontaneidad y la libertad de la expresión gestada fuera del marco que legitima al cartel... Cuando la represión o... la falta de acceso a los medios... silencian las voces del pueblo, las paredes murmuran, hablan, gritan» (Gándara, 2002:13).

Quizá la característica más interesante de este acontecimiento es su capacidad de formar parte de la memoria del movimiento estudiantil. Así, al iniciarse las movilizaciones del 2011, los/as estudiantes repiten la gesta histórica, colgando en el mismo lugar el lienzo con la frase «Chileno: 44 años después El Mercurio aún miente». De esta manera, los/as jóvenes no solo subvierten los discursos dominantes, sino que comprenden esta lucha simbólica como una parte fundamental de su acción colectiva circunscrita históricamente.

\section{ii) Brigadas gráficas y resistencia}

Las brigadas aparecen en Chile con una intención reivindicativa de apoyar o negar a un determinado grupo político y/o a una causa política. De esta manera, «proclamar su rechazo al poder o al gobierno de turno, su apoyo a tal partido o a tal movimiento, por medio del trazado de consignas, por medio de una presencia gráfica constante a través de la acción de brigadas murales, se convierte en un asunto emblemático de las prácticas de los años 60-70» (Araya, 2008:163). Es así como las brigadas constituyen una nueva forma de hacer propaganda política (Sandoval, 2001). 
En 1968, las Juventudes Comunistas de Chile formaron grupos de propaganda para movilizar a sus militantes, puesto que buscaban profundizar su rebelión y convertirse en jóvenes con conciencia revolucionaria. Para esto usaban formatos escritos de propagación de información. Un año más tarde, en 1969, nacen las Brigadas Muralistas Ramona Parra (BRP) en la denominada «Marcha por Vietnam». En este contexto, los/as jóvenes comunistas, socialistas, del MAPU, radicales y demócratas cristianos, estudiantes, campesinos y mineros, transitaron por la carretera desde Valparaíso a Santiago en contra del imperialismo ejercido por EE.UU., dejando mensajes visuales a medida que la marcha avanzaba. Estas intervenciones gráficas respondían, en suma, a la necesidad de plasmar la historia.

Según Sandoval (2001), la BRP fue la más popular y quizá la que alcanzó mayor continuidad a lo largo del tiempo. Organizada sobre la base de la estructura orgánica del partido, con jóvenes bien capacitados para realizar el trabajo de rayados en las calles, llegaron a ser las grandes protagonistas de los muros de los 70 . Desde entonces, se generan cada vez más facciones de la BRP en Chile. Esto sirve de impulso para que otras organizaciones políticas formen sus brigadas, y se alimente el movimiento popular y los devenires de la izquierda.

A partir de 1970, surgen nuevos grupos muralistas entre los que destacan las Brigadas Venceremos, compuestas por estudiantes y trabajadores, y la Brigada Elmo Catalán (BEC), como grupo de propaganda de las Juventudes Socialistas. Todos estos grupos apoyaron la candidatura de Salvador Allende por lo que, en conjunto, tapizaron Chile con la consigna «+ 3 ALLENDE VENCEREMOS»: «las distintas brigadas entonces entienden que la consigna debía ser una sola, para golpear con una misma finalidad. Es así como durante la semana previa a la elección presidencial, todos los miembros de las brigadas forman parte de la acción «Amaneceres venceremos» (Araya, 2008:165).

Esta decisión de hacer que todas las brigadas converjan en un mismo fin, da cuenta de una táctica momentánea por parte de los/as jóvenes insertos en el proyecto político de la UP, lo que culmina con la elección de Salvador Allende como presidente de Chile en 1970, reconocido internacionalmente por alcanzar el socialismo por una vía institucional. La lucha de la mayoría de los países, en este contexto, busca la utopía de la transformación social. Según Sandoval, durante el gobierno de la UP «el brigadismo pasó de ser una práctica de propaganda política a convertirse en un medio de expresión colectivo en el que participaron diversos grupos anónimos integrados por artistas, 
militantes, estudiantes y obreros comprometidos con el nuevo proyecto social» (2001:33).

Con el paso del tiempo, las brigadas se fueron distinguiendo por la estética que usaban: las BRP desarrollaron un muralismo cercano a la práctica de intención artística, a lo que la BEC reaccionó, primero intentando emular los murales de Ramona Parra, pero luego desarrollando una importante influencia del muralismo mexicano (Sandoval, 2001). La BRP siguió activa hasta que desapareció tras el golpe de estado de 1973. En lo sucesivo, muchos muros se cubrieron para ocultar ciertos pedazos de la historia (González, 2012). Junto con la represión militar, la prensa de oposición las atacó continuamente, de manera que hasta hoy, en algunos medios y registros, se ubica a las BRP y BEC como grupos violentistas y paramilitares (Sandoval, 2001). Lo que destaca de este periodo es la inclinación del trabajo brigadista hacia la consigna, pues su producción más extendida fue la de tomar el titular del diario como pauta orientadora, lo cual, junto con ser una forma de resistir a las elites político-mediáticas, constituía canales estratégicos de contrainformación (Castillo, 2006).

Años más tarde, en 1989, con la llegada del exilio de uno de los fundadores de la BRP, Danilo Bahamondes 'el gitano', nace la Brigada Chacón que utiliza la técnica del papelógrafo, la cual constituyó un mecanismo de seguridad dado su surgimiento aún en dictadura (Campos y Meller, 2007). En el contexto de transición democrática, los cambios producidos en la cultura política del país, así como en los propios partidos políticos, hicieron imperativa una reformulación de los antiguos códigos de comunicación política con que se manejaba la propaganda y los mensajes de las anteriores brigadas muralistas.

En este sentido, la Brigada Chacón fue pensada para funcionar en democracia (Sandoval, 2001). De acuerdo a Castillo (2006), el trabajo de la Chacón comprende una etapa que afina la propaganda callejera, valiéndose del derecho a opinar sobre el acontecer nacional, empleando estratégicamente los residuos mediáticos para ello. Esta brigada se ha caracterizado por su continuidad en el tiempo. Tras ella «existe una constante preocupación por contar con información que respalde los contenidos de los mensajes, además de un permanente contacto con el mundo social: la conversación cotidiana, sobre todo con los jóvenes; la observación de lo que día a día está ocurriendo en las calles» (Sandoval, 2001:56).

En síntesis, la especificidad de las escrituras expuestas en el pasado reciente chileno es la de conectar la acción política a un proyecto 
de transformación social que ha dejado huellas en la conciencia histórica colectiva. Sus actores han sido fundamentalmente jóvenes comprometidos/as con la lucha por un país mejor. Al respecto, resulta indispensable revisar el vínculo entre resistencia política y expresión juvenil, tal como se presenta a continuación.

iii) Discursos juveniles: expresión cultural e identitaria

Los/as jóvenes son creadores y portadores de sus propios mensajes, con los que han irrumpido en la esfera pública a través de distintos modos de comunicación. Estos van conformando identidades y memorias compartidas, que se actualizan permanentemente a través de medios y soportes variados. El uso de diferentes formas de protesta, que van desde la calle a las redes sociales (con el uso de textos, imágenes, corporalidades, performances, etc.), constituye una práctica discursiva notable que está reivindicando el poder juvenil, permitiéndoles la expresión directa de los significados con los cuales modelan qué tipo de vínculo los liga (y quieren que los ligue) a la sociedad actual (Cárdenas, 2014b).

La acción juvenil, pese a toda la evidencia académica que constata su presencia en el pasado reciente, ha sido persistentemente invisibilizada (Cárdenas, 2014a, 2011a). Esto da cuenta de un prejuicio adultocentrista (Duarte, 2012) que los/as ha negado como sujetos históricos de derecho propio. No obstante ello, los/as jóvenes han apropiado múltiples discursos con los que han manifestado no solo su cuestionamiento al sistema político-económico imperante, sino también el anhelo de un proyecto de sociedad diferente. En este sentido, han «culturizado» la política (Aguilera, 2014, 2010) para hacerse parte de los espacios públicos y resignificar su rol como ciudadanos. Las expresiones artísticas se han constituido, así, en maneras privilegiadas de construir sus utopías e ideales.

En este punto, «el graffiti da cuenta de una lógica intersticial de la vida juvenil» (Cruz, 2008:153). En cuanto forma de comunicación, el grafiti «permite la interacción de una sociedad juvenil que pasa por alto conscientemente las condiciones y normas de la sociedad en la que habitan. Éste guarda símbolos lingüísticos que hablan de colectividad, valor y búsqueda» (Cruz, 2008:153). Tal como sostiene Figueroa (2006), el grafiti es una práctica que ayuda a dar forma a las identidades de los/as jóvenes: a aquellas de carácter individual o grupal, como sucede con las agrupaciones hip-hop que se caracterizan por la 
escritura de «tags», y aquellas de carácter colectivo, que transcienden las experiencias locales para ir detrás de otras experiencias más memorables, como las que constituyen una lucha social común. Éste es el tipo de expresiones que se enmarcan en las movilizaciones estudiantiles de los últimos años.

La fuerza que han mantenido estas movilizaciones sigue en pie, y tiene directa relación con un proceso de maduración política por parte de los/as jóvenes, el que, como se ha visto, recupera demandas históricas de hace más de cuatro décadas. Por lo tanto, no es posible entender este hito en la historia de la educación en Chile por sí solo. Debemos contextualizarlo con una serie de procesos de largo aliento que tienen lugar en el plano político, social, económico y simbólico de la sociedad. Tales transformaciones, como hemos propuesto con anterioridad, tienen repercusiones culturales concretas, por ejemplo, en la expresión artística callejera. Conviene, entonces, preguntarse por la naturaleza comunicativa de estas expresiones, de manera tal de establecer sus interconexiones con una práctica de reivindicación política mucho más amplia.

\section{EL GRAFITI COMO PRÁCTICA COMUNICATIVA}

\section{a) El grafiti como discurso: necesidad analítica}

El grafiti constituye un discurso en virtud del medio (paredes, mobiliario) y la modalidad (escrita, icónica) que le otorgan materialidad y sentido, por lo tanto, siempre está situado cultural e históricamente, aspecto que enfatiza su escenificación como actividad social. Bajo estas premisas básicas, el grafiti requiere de un modelo elemental de la comunicación para su análisis. En esta línea, una de las primeras teóricas en proponer el grafiti como género discursivo es Regina Blume (1999). De acuerdo a su propuesta, existen siete parámetros para su caracterización:

i) Lugares: El grafiti se expresa generalmente en espacios exteriores, desde las murallas hasta la locomoción colectiva, no obstante, también existen presentaciones en muros interiores, en sillas, mesas, etcétera. En ambos casos, estos espacios se caracterizan por ser de dominio público, lo que permite una interacción particular dependiendo del caso y el lugar donde se produzca el grafiti. Por ejemplo, en las murallas de edificios céntricos y públicos, se genera una buena ocasión para plasmar una inscripción con contenido de protesta. 
ii) Formas: El grafiti es un texto escrito y su forma es variable. Sintácticamente, puede abarcar desde oraciones compuestas por una sola palabra, hasta oraciones completas. La corta extensión de estas frases puede explicarse por el tipo de superficie sobre la cual se escriben, además del tiempo que requiere hacerlas, puesto que, en su mayoría, los grafitis son desarrollados en secreto y en movimiento. En cuanto a su estructura textual, el grafiti puede relacionarse con los eslóganes publicitarios, por su brevedad y su finalidad: que se les recuerde con facilidad. En cuanto a su vocabulario, es rico en palabras consideradas tabú.

iii) Temática: No es posible establecer una relación directa entre fuentes y énfasis temáticos, no obstante, existen algunas tendencias que permiten correlacionar ciertos grafitis con contextos situacionales específicos, como lo son, por ejemplo, aquellas inscripciones en murallas de edificios gubernamentales que buscan atraer el interés general con algún motivo político; asimismo, las inscripciones con contenido personal las encontramos en espacios interiores como pupitres, retretes, etcétera.

iv) Autores: Con la excepción de algunos casos, el grafiti es una forma de expresión anónima, ni siquiera cuando se le es agregado un nombre permite la verdadera identificación de quien lo escribe. En general, es la expresión de una sola persona, pero en algunas oportunidades su carácter es colectivo, ligado generalmente con alguna actividad de tipo política.

v) Destinatarios: El autor, por lo general, no se dirige directamente a un lector en particular, tal vez sí a un grupo de personas. Además, no existe un lazo directo entre autor-lector; es decir, no se conocen. Por último, el lector tiene la posibilidad de contestar a lo que dice el texto, no sabiendo a quién se dirige, vale decir, es un anonimato recíproco.

vi) Motivos: Tanto en el grafiti de comunicación de masas como en el de comunicación reflexiva individual el autor hace una prueba de existencia, esto es, demuestra que él, como productor e interlocutor, se posiciona en el espacio comunicativo. En el primer caso, el autor escribe algún nombre que lo personaliza, en el segundo caso, la identificación es más bien grupal; el autor pretende hacerse parte de un colectivo, generalmente impulsado por el carácter político de una acción que comparte con otros miembros, donde se ejerce una búsqueda de contacto. Este tipo de autoría se corresponde habitualmente con grupos minoritarios, socialmente rechazados o marginalizados.

vii) Fuentes lingüísticas: Si el grafiti es considerado como un todo, son dos sus funciones del lenguaje más relevantes, a saber, la función cognitiva y la función poética. La primera busca enlazar el grafiti al 
contexto, expresando intencionadamente percepciones, sensaciones, recuerdos, proyectos, opiniones, etc., relevantes a una determinada situación social. La segunda resalta elementos retóricos como la parodia y la imitación de fórmulas determinadas (proverbios, refranes, etcétera) circunscritas culturalmente.

Dicho esto, creemos que para realizar un análisis del grafiti como discurso se debe recurrir al vínculo entre texto y contexto como foco principal. Esta perspectiva puede ser proporcionada por cualquier enfoque que entienda el discurso como una construcción situada, lo que nos hace optar por un análisis de los grafitis lingüísticos como productos sociocomunicativos, poniendo especial atención en los factores sociales, políticos e históricos subyacentes a ellos.

\section{b) El grafiti como contradiscurso: comprensión crítica}

Los grafitis se producen en contextos de problemáticas sociales que entrañan prácticas de dominación, control, discriminación, etc., por parte de unos grupos sobre otros. En este estudio esta forma de expresión se inserta en la acción política juvenil como un modo de protesta con intención de resistencia y como forma de contrapoder.

En este sentido, el marco teórico-metodológico más adecuado para analizar los grafitis lingüísticos como contradiscursos se corresponde con los Estudios Críticos del Discurso (ECD). En cuanto enfoque multidisciplinar, su preocupación está puesta en los conflictos de poder atravesados por la desigualdad social y el abuso, y en los mecanismos a través de los cuales se desarrollan prácticas contrahegemónicas (Van Dijk, 2009, 2003, 2000, 1996). Según Wodak, la crítica «ha de entenderse como el resultado de tomar cierta distancia respecto de los datos, enmarcar estos en lo social, adoptar explícitamente una postura política y centrarse en la autocrítica» (2003:29). Así, analizar críticamente los discursos corresponde a un posicionamiento del investigador que asume una conciencia de clase latente (Horkheimer, 2003). Se desprende, entonces, que los discursos institucionales, políticos o mediáticos, entre otros, testifican la existencia de pugnas materiales y simbólicas constantes entre diferentes grupos sociales. Develar estos conflictos y mostrar cómo funcionan en la comunicación se convierte en un compromiso del analista, pues éste se aboca a examinar cómo las construcciones discursivas se relacionan con las estructuras sociales, reproduciendo o resistiendo la imposición del poder. 
Para los ECD interesa el poder textualmente mediado, el cual se define «como una relación específica entre grupos sociales o instituciones. Es decir, ignoraremos... las diversas formas de poder personal entre individuos, a menos que esté basado en la pertenencia a un grupo» (Van Dijk, 2000:40). Desde esta perspectiva, el analista crítico se ocupa del uso ilegítimo del poder ejercido por unos grupos hegemónicos sobre otros, o sea, el abuso que estos practican.

No obstante, siguiendo a Van Dijk (2009), los grupos dominados y sus miembros rara vez carecen absolutamente de fuerza. «En determinadas condiciones socioeconómicas, históricas o culturales, tales grupos pueden comprometerse en diversas formas de resistencia, o sea, en el ejercicio del contrapoder que, a su vez, puede restar poder a los poderosos y hasta puede hacerlos vulnerables, como sucede cuando se produce una revolución»(2009:63, cursiva nuestra). De esta manera, estos grupos pueden desarrollar estrategias de disenso discursivo, tanto para desmantelar los discursos hegemónicos, exponiendo sus operaciones y manipulaciones, así como para confrontarlos mediante la contestación más o menos directa, actuando en la producción de sus propios contradiscursos.

En este sentido, realizar un análisis crítico de los grafitis como contradiscursos implica reparar en los usos políticos — contrahegemónicos - que dan cuenta de los conflictos de poder que se actualizan en el lenguaje, a partir de las formas de resistencia desarrolladas por los sujetos involucrados en su producción. Asimismo, resulta indispensable reparar en las preferencias ideológicas (van Dijk, 2008, 1999) y las definiciones identitarias de los miembros grupales (van Dijk, 2010), de manera de dilucidar las creencias y los sentidos de pertenencia que se implican en estos mensajes. Esta interrelación permite establecer conexiones explícitas entre el texto y el contexto, todas ellas mediadas por una interfaz sociocognitiva (van Dijk, 2012) que ayuda a articular los niveles macro y micro del análisis, tal como se explica a continuación.

\section{EL GRAFITI COMO OBJETO DE ESTUDIO}

\section{a) Niveles y categorías de análisis}

Como se ha indicado, este estudio busca analizar las dimensiones del grafiti lingüístico como práctica comunicativa y como práctica social. Para delimitar su dimensión comunicativa, nos abocamos a identificar 
los propósitos socio-comunicativos que caracterizan al grafiti como contradiscurso emergente, y a describir las estrategias lingüísticodiscursivas que son definidoras de estos mensajes. Para delimitar su dimensión social nos proponemos explicar sus alcances sociopolíticos en la conformación de ideologías e identidades grupales. Para ello partimos del supuesto de que la producción de grafitis en el contexto del Movimiento por la Educación en Chile (2011-2013) refiere de manera privilegiada las diversas representaciones sociales que son específicas de las luchas estudiantiles, a partir de las cuales los/as jóvenes se posicionan como actores capaces de influir en la sociedad como interlocutores legítimos.

El análisis se organiza así en tres niveles de construcción de significados: textual, co-textual y contextual.

- Nivel textual, se exploran tres estratos lingüísticos, a saber: a) semántica, tanto i) global, por medio del estudio de las macroestructuras (temas discursivos) y los tipos de descripción global (auto-representación positiva y hetero-representación negativa), como ii) local, a partir de la identificación de presuposiciones e implicaciones y perspectivas o puntos de vista, y iii) retórica, mediante la exploración de distintas figuras como la reduplicación, los juegos ortográficos, la asíndeton, la hipérbole, la ironía y la metáfora; b) pragmática, donde se examina la construcción de deixis (social, temporal y espacial), y; c) semiótica, donde se observa la expresión multimodal preferida (tipografía y color).

- Nivel co-textual, se asume que el grafiti pervierte un espacio físico que es a la vez ideológico, de allí que pueda ser estudiado dentro de una correlación territorial. Por ello el análisis considera el lugar de la inscripción en tanto a) espacio de resistencia, cuyos límites demarcan el sentido político de la escritura, y como b) espacio de discursividad, pues la ubicación del grafiti dentro de la ciudad construye continuidades o discontinuidades textuales que recuperan un significado extralingüístico que, no obstante, se añade a su elucidación global. Ambas categorías son propuestas para explicar que el simbolismo del espacio no se entiende solo en sentido iconológico (representación visual del grafiti), sino en el sentido de un recorrido (representación semántica del grafiti): los destinatarios pueden «leer» el espacio público donde el grafiti aparece, de manera tal que éste es el entorno más inmediato que orienta su interpretación.

- Nivel contextual se analiza siguiendo tres categorías centrales: a) participantes (identidades y relaciones de poder), b) actos, activi- 
dades e interacciones comunicativas (de habla, sociales y políticas); y c) cognición personal y social (conocimientos, ideologías e identidades). En base a estas distinciones, se asume una perspectiva sociocognitiva para definir el contexto; es decir, como una construcción mental de la situación representada en la comunicación. De este modo, reparamos en las cogniciones que son relevantes para el/la o los/as autores/as de los grafitis, pero no interpretamos la recepción de los destinatarios eventuales.

\section{b) Caracterización del corpus: delimitación y justificación}

El corpus recolectado para esta investigación corresponde a 25 fotografías de grafitis linguísticos, las cuales fueron tomadas en dos ciudades universitarias del centro-sur del país, Valdivia y Santiago, en el contexto del Movimiento por la Educación en Chile (2011-2013). Se accedió al corpus mediante la exploración personal que realizamos de las principales calles de ambas ciudades, principalmente aquellas aledañas a los recintos universitarios, entre octubre de 2011 y diciembre de 2013. En cuanto a la justificación de los criterios que permitieron la recolección del corpus, optamos por ciudades universitarias que evidenciaran una fuerte participación estudiantil en el periodo, y que, a su vez, pertenecieran a contextos geográficos distintos, de manera tal de contar con una mirada más general del fenómeno.

Entre los criterios de selección que consideramos, junto con los parámetros espacio-temporales ${ }^{1}$ inicialmente indicados, se encuentra que: a) los grafitis aludieran explícitamente al conflicto educativo señalado, y; b) en caso que la relación temática no fuera evidente, ésta diera

1 Nuestro análisis a distintos niveles deviene en interpretaciones que reconocen la dificultad de reconstruir las diversas situaciones de producción de los grafitis considerados. Esta dificultad no sólo se explica teóricamente por el desfase — natural - entre el momento de la inscripción y el momento de la lectura (y la captura) de los grafitis analizados, sino metodológicamente por el momento en que se aborda la investigación (2014). Por ello nos aproximamos al corpus desde una elucidación global del periodo de movilizaciones (2011-2013), con posterioridad a la recolección y el tratamiento de los datos. Por lo tanto, los resultados sintetizan fenómenos político-históricos condensados en estos tres años, en el contexto de una lucha que se comprende como un proceso en avanzada. Los desafíos de desarrollar a futuro un estudio que permita una interpretación situada - on line - de la producción de grafitis lingüísticos, suponen la incorporación de técnicas etnográficas que permitan abarcar esta complejidad. 
cuenta de aspectos vinculados como la precarización social sustentada por el lucro, la mercantilización de derechos sociales u otros alcances que establecieran una conexión entre el movimiento ciudadano impulsado por los/as estudiantes y las reivindicaciones políticas más amplias que se suscitaron en el marco de dichas movilizaciones.

Una vez seleccionados los veinticinco grafitis procedimos a su organización. Primero elaboramos fichas de identificación que indicaban: a) numeración (grafiti $1=\mathrm{G} 1$, etc.), b) ciudad y fecha de captura, y c) contenido lingüístico. Luego establecimos relaciones temáticas, a partir de su alusión más o menos directa al conflicto educativo. En este sentido, el orden previsto para el análisis no es ni temporal ni espacial, sino que está definido en relación con la progresión temática evidenciada en los grafitis agrupados. Con este criterio establecido, se aplicaron las matrices de análisis cuyas categorías referimos anteriormente.

\section{Resultados}

Los resultados se ordenan en cuatro dimensiones que sintetizan los temas discursivos a los que refieren los grafitis analizados: a) acción juvenil y educación; b) acción juvenil y resistencia; c) acción juvenil y política, y; d) acción juvenil y memoria. Para efectos de esta exposición elegimos profundizar en los grafitis que componen la primera dimensión, cuyas interpretaciones dan cuenta de las representaciones sociales más predominantes en el contexto de movilizaciones estudiado, y que permiten, a su vez, una lectura transversal de las dimensiones restantes. ${ }^{2}$

La dimensión acción juvenil y educación tiene como representación nuclear demostrar el rechazo al modelo educativo implantado durante la dictadura militar de Augusto Pinochet (1973-1990) en Chile. Sus principales alcances tienen que ver con: a) impugnar el sistema impuesto, b) generar crítica y oposición a la educación de mercado, y c) posicionar las demandas juveniles para la transformación educativa.

2 Cada una de las dimensiones constituye un conjunto de significados que pueden leerse en cadena o como parte de un continuиm. Estos ayudan a evidenciar diversos estadios de maduración o proyección del movimiento estudiantil, cada uno de los cuales configura modos determinados de comunicar la protesta juvenil. 


\section{a) Acción juvenil y educación: el rechazo a un sistema impuesto}

En este ámbito de acción juvenil se configuran dos representaciones nucleares sobre la educación. Por una parte, está la educación concebida por los grupos juveniles que reivindican los derechos sociales básicos como fundamentales en la vida en sociedad. Por otra parte, se halla el cuestionamiento al actual modelo educativo basado en el sistema capitalista implantado por las elites dominantes. Así también se inscriben ciertas demandas históricas perseguidas por el movimiento estudiantil, al tiempo que se proponen algunas soluciones para ellas. En términos generales, importa destacar cómo los/as jóvenes no solo rechazan un sistema impuesto política y económicamente, sino que, además, cómo resisten dicha imposición comunicando estratégicamente sus reivindicaciones a la ciudadanía. El análisis de esta dimensión se desglosa en tres apartados, cada uno de los cuales recupera algunos de sus ejemplos más representativos.

\section{i) Nuestra educación v/s la educación de ellos}

Los grafitis que aluden de forma global a la educación tienen como principal propósito socio-comunicativo dar cuenta de una disconformidad general con el modelo educativo actual. Por ejemplo, en: G2: LA EDUCA\$IÓN ES UN DERECHO Y G5: VIOLENTA ES TU EDUCACIÓN DE MERCADO!! se muestran dos formas de entender la educación: «la nuestra» (educación como derecho); y «la de ellos» (educación como mercado). Ésta es la oposición ideológica elemental que se desprende de todos los grafitis que persiguen rechazar el tipo de educación imperante en Chile.

En primer lugar, G2 tiene como finalidad dar cuenta de la forma en que los/as jóvenes conciben la educación alejada de los márgenes empresariales. Se construye así un discurso que reivindica la educación como derecho social consagrado universalmente. Paralelamente, G2 funciona como un contradiscurso en la medida en que busca plantear a la ciudadanía disidencia respecto de lo que se ha estabilizado en la sociedad como único modelo educativo posible.

A nivel semántico, las presuposiciones ayudan a comprender cómo es juzgado dicho modelo, es decir, nos contextualizan frente a aquello que se impugna y nos permiten suponer que la otra educación que se implica es aquella vista como un bien de consumo, tal como se ha dado a conocer en otros discursos públicos en la administración de 
Piñera (2010-2014). En G2 se emplea el recurso retórico de la ironía para subvertir los significados hegemónicos, mediante la exposición de un juego simbólico (EDUCA\$ION) tendiente tanto a evidenciar el carácter neoliberal de la educación presente, así como a rechazar su imposición y naturalización.

A nivel pragmático, la deixis temporal implícita ayuda a reafirmar esta idea de falsa legitimación del modelo educativo, y nos ayuda a comprender por qué los/as jóvenes unifican su rechazo al reivindicar la educación como un derecho social inmanente. Sobre todo, si se considera que en algún momento de la historia este derecho se consagró constitucionalmente en Chile, perdiéndose tras la instauración de la dictadura militar. Así, el movimiento estudiantil retrotrae sistemáticamente saberes y memorias compartidas para perfilar las transformaciones políticas futuras, en la medida en que esta conciencia histórica comporta una base sociocognitiva que conecta intergeneracionalmente con otras representaciones juveniles del pasado reciente.

A nivel semiótico, el uso del signo peso (\$) es empleado para ironizar en torno al paradigma neoliberal que fundamenta el actual sistema educativo, con el fin de generar una contradicción explícita entre los sistemas de creencias de quienes se alinean y se oponen a la mercantilización de la vida social. Este ejemplo demuestra la postura más predominante frente a la lucha por una educación gratuita y de calidad, activando un conjunto de valores y actitudes ideológicas que giran en torno a la oposición capitalista/anticapitalista: por una parte, se observan posturas que valoran la propiedad y la movilidad social, mientras que, por otra, se identifican posturas preocupadas por la justicia y el desarrollo social.

En segundo lugar, G5 entrega información acerca de cómo es esta educación que «rechazamos» y que se confronta a «la que demandamos». Con ello se hetero-representa negativamente la concepción dominante; es decir, «TU EDUCACIÓN DE MERCADO» expuesta como un bien apropiado por las elites político-económicas.

A nivel semántico, la metáfora de la violencia supone una concepción de educación que agrede a las personas en sus derechos fundamentales. Dicha agresión no es física - aunque se exprese materialmente - sino más bien abstracta, debido a que afecta simultáneamente diversos ámbitos del desarrollo humano. Analizar este recurso retórico en su contexto nos permite trazar referencias intertextuales con otro discurso sostenido por «ellos», que dice relación con la idea de que los grupos dominados, en su afán por rechazar los órdenes 
establecidos, actúan de forma violenta frente al Estado y sus conglomerados políticos. De este modo, se reconocen dos posiciones confrontadas en el eje institucional/antisistema: la primera desmantela la metáfora del padre estricto (el Estado) que condena y castiga la desobediencia estudiantil, mientras que la segunda genera un correlato con la desinformación, deconstruyendo la fabricación de estereotipos que desvirtúan y alienan la percepción ciudadana, como sucede con las representaciones que vinculan a los/as estudiantes con hechos de desorden y destrucción. De allí que G5 venga a contradecir los significados hegemónicos conferidos a la violencia, mediante la siguiente contestación juvenil: «lo verdaderamente violento es el sistema educativo que padecemos, y no los/as estudiantes que luchamos para cambiarlo».

A nivel pragmático, el sentido de posesión que comporta el deíctico «tu» [educación] permite sostener que, efectivamente, la confrontación entre ambos grupos ideológicos es latente, y que ésta no puede mirarse únicamente desde lo conceptual, sino también desde las agencias, es decir, en base a la distinción de los actos violentos que configura, evalúa y condena cada fracción. Esto nos advierte que «los dueños» de esta educación «de mercado» son aquellos que llegan a destituir un modelo educativo igualitario que en el pasado fue accesible para todos/as, sugiriendo otra oposición implícita entre las reformas educativas impulsadas por el Gobierno de la Unidad Popular y las contrarreformas educativas implantadas por la dictadura militar. Lo que se desprende de dicha oposición es la necesidad de redimensionar la violencia y recontextualizarla en la lucha estudiantil actual, con todos los resabios dictatoriales — constitucionales y de terrorismo de estado- que se actualizan en dicha representación.

A nivel semiótico, el uso de una tipografía de letras grandes y en mayúsculas junto con los signos de exclamación funciona para connotar a la ciudadanía un carácter de denuncia y vociferación. Este sentido de urgencia implicado en G5 actualiza la necesidad de plasmar mensajes que no pueden comunicarse por otro medio, dado que los principales consorcios periodísticos son propiedad de las elites político/empresariales objetos del ataque. Las paredes, por tanto, se perfilan como una canal contra-informativo especialmente privilegiado, y como principal enclave de la resistencia callejera estudiantil.

Con respecto al análisis de G2 y G5 en sus niveles co-textuales y contextuales, interesa profundizar en algunos alcances socio-políticos que resultan sobresalientes. En cuanto a su inscripción en el espacio público, se emplean fachadas de edificios públicos tanto para validar la 
lucha estudiantil, deslegitimando la concepción de mercado que se sobrepone a los derechos sociales, como para representar confrontación y repudio frente a la criminalización mediática de la supuesta violencia ejercida por el movimiento.

En cuanto al modelamiento del contexto comunicativo, la confrontación entre los intereses de los participantes confirma la disputa de dos representaciones opuestas, fundamento de la polaridad ideológica que sustenta las movilizaciones: nuestra educación $=$ nuestro derecho $\mathrm{v} / \mathrm{s}$ la educación de ellos $=$ su mercado . Los grafitis hacen inteligible esta distinción porque es la manera a través de la cual la ciudadanía puede tomar partido, esto es, identificarse con un modo u otro de concebir la educación.

Estos discursos juveniles proponen a la sociedad significados alternativos a los que circulan habitualmente en la esfera pública, donde la educación cimentada sobre un modelo neoliberal se ha estabilizado, haciéndose - hasta hace poco - incuestionable. De allí que G2 y G5 busquen desmantelar esta visión dominante, conectando la acción juvenil a dos objetivos colectivos centrales: reivindicar la educación como un legítimo derecho, y denunciar que el mercado es el principal reproductor de abusos y desigualdades sociales.

ii) Crítica y oposición a la educación de ellos

En la misma dimensión temática se presentan otros grafitis que persiguen la eliminación de «la educación de ellos (su mercado)». Este propósito sociocomunicativo se ejemplifica de buen modo en G7: LA EDUCACION MATA A LOS NIÑOS; G9: DESTRUYAMOS LA EDUCACION DE MERCADO A ${ }^{3}$ y G10: DESTRUIR LAS ESCUELAS, AuToeduKaTe A. Estos grafitis dan cuenta no solo de la oposición y la crítica al sistema educativo vigente, sino que, además, funcionan como un llamado de atención (G7) y un llamado a la acción (G9 y G10) para quienes construyen solidaridad ideológica con tales consignas.

En primer lugar, en G9 se invoca a poner término a la educación de mercado mediante «nuestros» actos colectivos, capaces de desestabilizar y demostrar la obsolescencia de la lógica empresarial que coarta los derechos que «nos pertenecen». En segundo lugar, G10 pone énfasis ya no en el mercado, sino en el sistema institucionalizado de la educación en todos sus niveles. Así se genera una relación directa con

3 Letra utilizada en la transcripción para representar el símbolo anarquista. 
G7, en tanto que ambos ponen en cuestión el modelo que regula los procesos de escolarización en Chile.

En este punto llama la atención que la utilización de escasos referentes (educación, mercado, derechos) activen una gran cantidad de conocimientos previos, precisamente porque los objetivos del movimiento estudiantil se han enfocado en comunicar a la ciudadanía los parámetros mínimos para comprender sus demandas. La introducción de estos términos en los discursos públicos y cotidianos constata no solo una importante capacidad de difusión y socialización política, sino que también procura el dominio de marcos de interpretación que resultan afines a la lucha juvenil, de allí que estas nociones adquieran sentido a partir de esos entornos cognitivos compartidos.

A nivel semántico, importa profundizar en cómo G9 y G10 plantean la metáfora de la destrucción. En este sentido, la estructura retórica se usa para poner en crisis una concepción de educación abusiva que es vertical en su forma y que se basa en el condicionamiento de las personas. De acuerdo con ello, la destrucción implica a su vez una (re)construcción; no se plantea destruir la educación en sí misma, sino aquella que lucra funcionando como una empresa; al mismo tiempo, no se plantea destruir todas las escuelas, sino aquellas que responden al proyecto educativo que se estandariza por medio de mediciones que correlacionan la capacidad de enseñanza con la capacidad de pago de las familias. De este modo, la destrucción se plantea en ambos casos como una apertura a la transformación y al cambio social.

A nivel pragmático, la deixis personal constata una polaridad implícita reiterativa (nosotros/ellos), que funciona como fundamento de la disputa ideológica en torno a la refundación del sistema educativo. Asimismo, la deixis temporal implícita supone que «ahora» es el momento de lucha indicado para llevar adelante dicha refundación, de allí su carácter urgente y colectivo. Ello permite evidenciar que el llamado a la acción es permanente y apremiante, es decir, que los discursos configurados por los/as jóvenes no solo evalúan y denuncian la situación presente de desigualdad y abuso, sino que, además, apelan a un sentido performativo: generamos este cambio a medida que peleamos por él.

A nivel semiótico, G9 y G10 utilizan el color negro sumado al símbolo «A» que asume la producción de los mensajes desde una concepción anarquista. Esta estrategia advierte que los/as jóvenes se alejan de la mera crítica por la crítica basada en desobediencia civil, y reivindican una ideología política anarquista que, desde los significa- 
dos dominantes estabilizados en la sociedad, tiende a adquirir un carácter negativo. No obstante, esta reivindicación es positiva si se observa a la luz de un análisis que rescata precisamente el llamado a la acción, en tanto demuestra cómo los/as jóvenes se alejan de la simple disidencia y proponen soluciones. En este punto es interesante retomar la propuesta de autoeducación vinculada con los principios anarquistas de acción directa y autogestión, con lo cual se desvela la necesidad de los/as estudiantes de plantearse activos frente a aquello que no comparten del sistema, perfilando su modificación.

Con respecto al análisis de G7, G9 y G10 en sus niveles cotextuales y contextuales, importa profundizar en varios alcances sociopolíticos que resultan prominentes. En cuanto a los espacios de resistencia representados, G7 se emplaza en un jardín infantil, lo que permite establecer relaciones explícitas con los conocimientos compartidos que se desprenden de esta interpelación simbólica, enfatizando en su función subversiva. Se persigue, por tanto, cuestionar tanto el enquistamiento de un modelo segregador, como la naturalización de una escolarización temprana solventada en metodologías pedagógicas ineficientes y deficitarias. Se repite la elección estratégica del lugar de exposición en G10, donde se ha escogido la muralla que une un liceo con una escuela pública, lo que amplía la representación contrahegemónica de las instituciones educativas, produciéndose el mismo cuestionamiento en torno al sentido de la escolarización y sus parámetros pedagógicos viciados. Se vuelve a reivindicar la concepción de educación como derecho social, y se plantea que en tanto este sistema funcione bajo las lógicas del sector económico dominante, la educación que se demanda debe ejercerse en base a la autogestión.

En relación con el conocimiento de mundo compartido por los participantes, se construyen representaciones que atacan la educación en términos institucionales $\mathrm{y}$, con ello, los márgenes curriculares que la rigen. De este modo, se plantea que el ingreso de los/as niños/as al sistema escolar impuesto genera un estancamiento de los aprendizajes necesarios para una vida en sociedad, razón por la cual se construye negativamente a la escuela como una entidad que los/as homogeneiza y constriñe sus potencialidades. Estos grafitis constituyen, entonces, un contradiscurso que busca plantear a la ciudadanía una crítica a la escolaridad, en tanto que promueve el adiestramiento más que el desarrollo del pensamiento crítico, la creatividad y la imaginación. En estos términos se llama a la creación de un nuevo proyecto educativo - gratuito, laico y de calidad-, fuera de las concepciones empresaria- 
les, lo que busca generar adhesión de parte de los sectores mayoritarios de la sociedad, alineados con la idea de cambiar un sistema basado en la estandarización y la competencia.

En síntesis, los alcances sociopolíticos que predominan en estos primeros ejemplos se actualizan de manera similar y articulada: en algunos casos son idénticos — como cuando se apela a la destrucción del mercado-, y cuando difieren, estos igualmente convergen en una lectura coherente que provee versiones alternativas del conflicto educativo. Los ejemplos que se analizan en el próximo apartado también conforman la dimensión de acción juvenil y educación, pero adquieren otros matices: si hasta aquí los grafitis han buscado delimitar la pugna ideológica por la educación deseada, particularmente sus participantes y acciones, a continuación se relacionan con demandas específicas que prefigura el movimiento estudiantil de postdictadura.

iii) Nuestras demandas de transformación educativa

Otro de los propósitos sociocomunicativos observados dice relación con instalar las demandas históricas del Movimiento por la Educación en Chile, cuyos objetivos se visibilizan masivamente a partir de la Revolución Pingüina del 2006. Desde entonces, dichas demandas se han estructurado en tres ejes principales: financiamiento, acceso y autonomía.

Los/as jóvenes disputan estas exigencias instalándolas en las calles con un sentido explícitamente contrainformativo: por ser demandas que surgen desde los sectores dominados y menos favorecidos, y que afectan directamente los intereses de las elites políticas, empresariales y mediáticas que controlan la exposición pública del conflicto educativo, tienden a no ser tratadas en los medios oficiales, subsumiéndose estos mensajes a espacios alternativos de difusión y circulación. Ejemplos de este propósito son G13: DESMUNICIPALIZACIÓ AHORA!! $\mathrm{X}^{4}$ IZQUIERDA COMUNISTA, G16: MUERTE A LA P\$U \$ Y A LA CACADEMIA, y G20: NACIONALIZAR EL COBRE PARA FINANCIAR LA EDUCACIÓN.

En primer lugar, G13 tiene como finalidad instalar una demanda que apela a la autonomía de las instituciones educativas específicamente a nivel secundario, la cual reivindica la educación pública entendida como aquella que depende administrativamente del Estado. Este grafiti reitera una exigencia emplazada sistemáticamente por las

4 Símbolo utilizado en la transcripción para representar el logo del partido político Izquierda Comunista. 
movilizaciones estudiantiles en las últimas décadas, que si bien es de conocimiento común, implica un requerimiento altamente controversial ya que afecta los intereses económicos de la mayoría de los grupos que controlan la educación subvencionada y particular, de allí que se convierta en un objeto de desinformación mediática.

En segundo lugar, G16 enfoca esta crítica concretamente en la educación superior, en tanto apela a su acceso bajo estándares que no miden realmente la capacidad intelectual de los/as estudiantes, sino que condiciona su posibilidad de ingreso a su capacidad de pago, es decir, a qué clase de escolarización asegura la entrada a la universidad. Este grafiti reclama la eliminación de la Prueba de Selección Universitaria (P\$U), al tiempo que cuestiona la calidad de los estudios a los que es posible aspirar a lo largo de la formación profesional (cacademia).

En tercer lugar, G20 expone una demanda estudiantil que sobresale especialmente en el último ciclo movilizatorio, la cual tiene la particularidad de sobrepasar el ámbito meramente educativo, perfilándose como una exigencia capaz de impactar en diversos niveles de la sociedad. Esto se explica porque la petición de nacionalizar el cobre, y con él otros recursos naturales propios, permitiría no solo dar solución a la principal necesidad que plantea el Movimiento por la Educación: la gratuidad, sino que, además, podría garantizar el acceso a otros derechos fundamentales (salud, vivienda, etcétera). Así, G20 exhibe una exigencia colectiva que compromete no solo a los/as estudiantes, sino también a otros actores clave, como los/as trabajadores/as, articulando dos sectores sociales históricamente involucrados en los procesos de movilización ciudadana, cuestión que ayuda a dotar de transversalidad a tales reivindicaciones.

A nivel semántico, destaca el uso de algunos recursos retóricos que resultan comunes. Por una parte, la asíndeton ayuda a entregar un mensaje conciso y rápido de leer como bien ejemplifica G13, pues, con apenas dos palabras: «desmunicipalización» y «ahora», se activan diversos conocimientos compartidos que recontextualizan esta demanda en el marco de una dilatada lucha estudiantil. Con similares propósitos, la asíndeton sintetiza en G20 un conjunto de presuposiciones e implícitos fácilmente recuperables del pasado reciente, como sucede con la estatización de la gran minería del cobre consagrada en 1971 bajo el gobierno de Allende. Por otra parte, la metáfora de la muerte en G16, al igual que la metáfora de la destrucción en G9 y G10, simboliza la total eliminación de los enclaves representativos de la educación de mercado, como es el caso de la PSU y, por extensión, 
una academia que hace posible la pervivencia de un sistema de educación superior cuya calidad ha sido crecientemente cuestionada.

A nivel pragmático, la deixis temporal presente explícita o implícitamente en los tres ejemplos connota el carácter apremiante de las demandas sostenidas durante los años consecutivos de movilizaciones. Ello permite evidenciar que el llamado a la transformación del modelo educacional es permanente y siempre inminente, y que su reiteración acusa una actitud de indiferencia condicionada por las elites hegemónicas comprometidas con la crisis de la educación, es decir, que si las exigencias son sistemáticamente visibilizadas, su reposición advierte una nula reacción por parte de los sectores político-económicos que reproducen el modelo neoliberal consignado como responsable de las desigualdades y los abusos perpetrados.

A nivel semiótico, es necesario hacer referencia a la repetición del uso de mayúsculas, que intenciona el carácter de vociferación (el grito) y la denuncia. Otro uso frecuente es la selección del signo peso (\$), que al igual que en G2, se emplea en G16 para ironizar en torno al actual sistema educativo que limita el desarrollo profesional a la condición económica de las personas, potenciando que la segregación se agudice en el transcurso de la formación universitaria. Este alcance se desprende del concepto «cacademia» en G13, cuyo juego ortográfico se desprende de la relación entre la caca (excremento) y la academia, potencializando su valoración negativa.

Con respecto al análisis de G13, G16 y G20 en sus niveles cotextuales y contextuales, llamamos la atención sobre varios alcances sociopolíticos prominentes. En cuanto a los espacios de resistencia representados, son utilizadas fachadas de oficinas públicas para connotar subversión ante las clases gobernantes que pactan con los grupos dominantes para resguardar sus intereses, beneficios y bienes. En cuanto a los participantes, sus actos y los conocimientos de mundo que comparten, queda explícita la base ideológica que modula las exigencias comunes a los diferentes actores sociales: estudiantes secundarios, universitarios y trabajadores. Si bien hoy por hoy se reconoce esta articulación como una característica distintiva de las recientes movilizaciones ciudadanas, los/as jóvenes subrayan constantemente la naturaleza transversal de sus reivindicaciones, con el objetivo de generar un contrapeso político que legitime los cambios estructurales perseguidos sobre la base de la adhesión mayoritaria y el apoyo popular. 


\section{CONCLUSIONES}

Este estudio se ha interesado por analizar discursos de protesta callejera en forma de grafitis linguísticos, elaborados en el contexto del Movimiento por la Educación en Chile (2011-2013). Su producción se ha abordado no solo como práctica comunicativa, sino también como práctica social situada, lo que ha permitido explorar los alcances sociocognitivos, sociopolíticos y sociohistóricos que caracterizan las representaciones formuladas por los/as jóvenes, en una coyuntura donde se despliegan como enunciadores y actores legítimos.

Los resultados permiten sintetizar, por un lado, que los grafitis comunican un estado de consciencia frente al modelo educativo impuesto, esto es, tienen como principal objetivo instalar un sentido de crisis y conflicto, de manera tal de desnaturalizar la idea de un sistema incuestionable e inamovible. Por otro lado, estos grafitis buscan construir solidaridad ideológica con otros grupos que comparten similares conocimientos de fondo, memorias, valores y actitudes, para así sumar actores sociales a una lucha ciudadana que se plantea como vía privilegiada para la consecución de transformaciones sustantivas. De este modo, al visibilizar públicamente sus impugnaciones y demandas, los/as estudiantes prefiguran un nuevo proyecto nacional de educación pública, en base a la gratuidad, la inclusión, la autogestión y la calidad.

Se desprende del análisis que las representaciones juveniles postulan interpretaciones que contradicen o reformulan los discursos de autoridad; así, cuando cuestionan el sistema educativo imperante, proponen una ruptura cultural que instala nuevos paradigmas de comprensión, relativos a oposiciones tales como gratuidad/lucro, derecho/bien de consumo, acceso/selección, calidad/cobertura, homogeneización/autodeterminación, entre otras. Con ello, los/as jóvenes visibilizan una crisis política que desafía otras oposiciones del tipo violencia/re-sistencia, censura/contrainformación y dominación/disidencia, al tiempo que apelan a la rememoración para reivindicar su conciencia histórica y tensionar un conjunto de saberes vinculados con las oposiciones pasado/futuro, memoria/olvido, democracia/dictadura, etc.

Esto se debe a que los grafitis, mediante una configuración textual sintética pero rica en presuposiciones e implicaciones, activan múltiples efectos sociocognitivos a través de diversos usos retóricos, deícticos y multimodales que ayudan a delimitar la oposición entre los participantes (nosotros/ellos), sus actos y conocimientos estructurados ideológicamente. Así, a nivel semántico, los grafitis se caracterizan 
por emplear múltiples inferencias, metáforas e ironías que configuran una confrontación central: la autorrepresentación positiva de nosotros (los/as jóvenes, los/as estudiantes), y la hetero-representación negativa de los otros (las élites políticas, económicas y mediáticas). A nivel pragmático, el uso de la deixis permite situar las condiciones críticas del conflicto educativo (su lugar, tiempo y adversarios principales), con un sentido de inmediatez, urgencia y permanencia. A nivel semiótico, la tipografía y el color son recursos claves para demarcar el sentido de pertenencia de los productores discursivos (comunismo, anarquismo), posición desde la cual se evoca la vociferación y la contestación sistemáticas.

Estos usos modelan representaciones sociales compartidas por grupos que demuestran una posición política de izquierda, cuya principal creencia promueve una visión de la sociedad basada en la igualdad y el respeto por los derechos sociales y humanos. Estas creencias comunes modulan, a su vez, la construcción de dos tipos de identidades fundamentales: de generación (juvenil) y de clase (popular). Con ello se estructura la oposición entre quienes representan la clase dominante - adulta y acomodada - y quienes resisten esta dominación y luchan por la implantación de un nuevo proyecto de sociedad basado en los ideales revolucionarios apropiados por la juventud - específicamente aquella de las capas medias y bajas-.

En suma, los/as jóvenes, al apropiarse del espacio público mediante la producción de grafitis lingüísticos, subvierten los significados hegemónicos toda vez que amplían el campo del conocimiento social con otras representaciones relativas al conflicto estudiantil, entregando a la ciudadanía discursos alternativos que les permiten acceder a otros modos de aprehender y dar sentido a la realidad cuestionada. De este modo, el grafiti se constituye como un contradiscurso que persigue la resignificación de los discursos dominantes, con el fin de resistir su aceptación y naturalización social.

VALDIVIA (CHILE), DICIEMBRE 2014

RECIBIDO: DICIEMBRE 2014 ACEPTADO: JUNIO 2015 


\section{REFERENCIAS BIBLIOGRÁFICAS}

ABARCA, LUIS y JUAN FORCH (1972): Viaje por la juventud. Santiago: Quimantú.

ACHUGAR, MARIANA (2006): «Entre la memoria y el olvido: las luchas por la memoria en el discurso militar uruguayo, 1976-2001». En E. HERSHBERG y F. AGÜERO (coordinadores): Memorias militares sobre la represión en el Cono Sur: visiones en disputa en dictadura y democracia. Madrid: Siglo XXI.

AGUILERA, ÓSCAR (2014): Generaciones: movimientos juveniles, políticas de identidad y disputas por la visibilidad en el Chile neoliberal. Buenos Aires: CLACSO.

(2012): «Repertorios y ciclos de movilización juvenil en Chile (20002012)». Revista Utopía y Praxis Latinoamericana, Vol.17, №57. Maracaibo: Universidad del Zulia.

- (2010): «Cultura política y política de las culturas juveniles». Revista Utopía y Praxis Latinoamericana, Vol. 15, N50. Maracaibo: Universidad del Zulia.

- (2009): «Los estudios sobre juventud en Chile: coordenadas para un estado del arte». Última Década №31. Valparaíso: Ediciones CIDPA.

Agurto, Irene, MANuEl CANALES y GonZAlo de la MAZA (1985): Juventud chilena. Razones y subversiones. Santiago: ECO/FOLICO/SEPADE.

ARAYA, PEDRO (2008): «El Mercurio miente (1967): siete notas sobre escrituras expuestas». Revista Austral de Ciencias Sociales NN$^{\circ} 14$. Valdivia: Universidad Austral de Chile.

BAEZA, JORGE y MARIO SANDOVAL (2009): «Nuevas prácticas políticas en jóvenes de Chile: conocimientos acumulados 2000-2008». Revista Latinoamericana de Ciencias Sociales, Niñez y Juventud. Manizales: Universidad de Manizales, CINDE.

BALARDini, SERgio (2000): «De los jóvenes, la juventud y las políticas de juventud». Última Década $\mathrm{N}^{\circ} 13$. Valparaíso: Ediciones CIDPA.

BELlei, CRISTIÁN, CRISTIAN CABALIN y VÍCTOR ORELlANA (2014): «The 2011 Chilean Student Movement against Neoliberal Educational Policies». Studies in Higher Education, Vol. 39, N³. Routledge: Taylor y Francis.

- y - (2013): «Chilean Student Movements: Sustained Struggle to Transform a Market-oriented Educational System». Current Issues in Comparative Education, Vol. 15, №2. New York: Columbia University.

Blume, REGINA (1999): «Graffiti». En T. VAN DIJK (editor): Discurso y literatura. Madrid: Visor.

CABAlin, Cristian (2014): «The Conservative Response to the 2011 Chilean Student Movement: Neoliberal Education and Media». Discourse: Studies in the Cultural Politics of Education, Vol. 35, N²4. Routledge: Taylor y Francis. 
-(2012): «Neoliberal Education and Student Movements in Chile: Inequalities and Malaise». Policy Futures in Education $\mathrm{N}^{\circ} 10$. Oxford: Symposium Journals.

CAlveiro, Pilar (2008): «La memoria como futuro». Actuel Marx Intervenciones $\mathrm{N}^{\circ} 6$. Santiago: LOM.

Campos, Edwin y Alan Meller (2007): Santiago stencil. Santiago: Cuarto Propio.

CÁRDENAS, CAMILA (2014a): «Jóvenes e (in)visibilización histórica: modos de representación ideológica de la juventud chilena en el pasado reciente (1970-1990)». Revista Signos. Estudios de Lingüística, Vol. 47, №5. Viña del Mar: Pontifica Universidad Católica de Valparaíso.

(2014b): «Representación de la acción política de los estudiantes chilenos. Movilización de significados en redes sociales». Última Década $\mathrm{N}^{\circ} 40$. Valparaíso: Ediciones CIDPA.

(2013): «La representatividad en disputa: estrategias conversacionales de dos líderes juveniles en una interacción política televisada». Revista Discurso \& Sociedad, Vol. 7, №3.

(2011a): «(In)visibilización juvenil: acerca de las posibilidades de las y los jóvenes en la historia reciente del país». Última Década $\mathrm{N}^{\circ} 35$. Valparaíso: Ediciones CIDPA.

— (2011b): «De visualizaciones y visibilizaciones: lectura del movimiento estudiantil chileno a partir de dos documentales». Revista Guionactualidad [online]. Barcelona: Universitat Autònoma de Barcelona.

Castillo, Eduardo (2006): Puño y letra. Movimiento social y comunicación gráfica en Chile. Santiago: Ocho Libros Editores.

Chaves, MARIANA (2005): «Juventud negada y negativizada: representaciones y formaciones discursivas vigentes en la Argentina contemporánea». Última Década N²3. Valparaíso: Ediciones CIDPA.

CRUZ, TANIA (2008): «Instantáneas sobre el graffiti mexicano: historias, voces y experiencias juveniles». Última Década N²9. Valparaíso: Ediciones CIDPA.

Domedel, ANDREA, MACARENA PEÑA y LiLlo (2008): El mayo de los pingüinos. Santiago: Ediciones Radio Universidad de Chile.

DUARTE, ClAUdIO (2012): «Sociedades adultocéntricas: sobre sus orígenes y reproducción». Última Década $\mathrm{N}^{\mathrm{0}} 36$. Valparaíso: Ediciones CIDPA.

ESCAMILLA, JULIO (2013): «Grafiti colombiano contemporáneo versus medios de comunicación». Ponencia presentada en Journées d'études ADAL: Analyse des discours de l'Amérique Latine. París, Francia.

FIGUEROA, GRICELDA (2006): Sueños enlatados: el graffiti hip hop en Santiago de Chile. Santiago: Cuarto Propio.

GÁNDARA, LELIA (2002): Graffiti. Buenos Aires: Eudeba.

GARCÉS, MARIO (2013): «El movimiento estudiantil y la crisis de legitimidad de la política chilena». Revista Pensar Historia No2. Medellín: Universidad de Antioquía. 
GARretón, MANUEl ANTONiO et al. (2011): «Movimiento social, nuevas formas de hacer política y enclaves autoritarios. Los debates del Consejo Asesor para la Educación en el gobierno de Michelle Bachelet en Chile». Polis. Revista Latinoamericana, Vol. 10, №30. Santiago: Universidad de Los Lagos, CISPO.

GONZÁLEZ, YANKO (2011): «Primeras culturas juveniles en Chile: pánico, malones, pololeo y matiné». Revista Atenea N503. Concepción: Universidad de Concepción.

- (2010): «'Sumar y no ser sumados': culturas juveniles revolucionarias. Mayo de 1968 y diversificación identitaria en Chile». Revista Alpha No30. Osorno: Universidad de Los Lagos.

_ (2002): «Que los viejos se vayan a sus casas. Juventud y vanguardias en Chile y América Latina». En C. FeIXA, M. Costa y J. SAURA (editores): Movimientos juveniles: de la globalización a la antiglobalización. Barcelona: Ariel.

GonZÁleZ, PATRICIO (2012): «De la academia a la calle». Memoria para optar al título de pintor. Santiago: Universidad de Chile.

HorkHEIMER, MAX (2003): Teoría crítica. Buenos Aires: Amorrortu.

LATORRE, JUAN IGNACIO (2013): «Moviment estudiantil: Re-polititzant la societat xilena». Educació Social. Revista d'Intervenció Socioeducativa No55. Barcelona: Universitat Ramon Lull.

LÓPEZ, REBECCA (2014): «Una aproximación al movimiento por la educación en Chile (2011-2013): análisis crítico de los discursos de protesta callejera en forma de grafiti lingüístico». Ponencia presentada en VIII Encuentro Nacional de Estudios del Discurso. Estudios del discurso: Aplicaciones educativas y clínicas. Valparaíso, Chile.

MARGULIS, MARIO y MARCELO URRESTI (1996): La juventud es más que una palabra. Ensayos sobre cultura y juventud. Buenos Aires: Biblos.

MARTín ROJO, LuISA (2013): «Paisajes lingüísticos de indignación. Prácticas comunicativas para tomar las plazas». En S. AGUILAR (editor): Anuario del conflicto social 2012. Barcelona: Observatorio del Conflicto Social, Universidad de Barcelona.

MAYOl, AlBerto y CARLA AzÓCAR (2011): «Politización del malestar, movilización social y transformación ideológica: el caso Chile 2011». Polis. Revista Latinoamericana, Vol. 10, №30. Santiago: Universidad de Los Lagos, CISPO.

Millán, CeCilia (2010): «Política y sueños colectivos: miembros de las generaciones del 70 y del 90». Última Década №32. Valparaíso: Ediciones CIDPA.

MuÑOZ, VíCTOR (2011): «Juventud y política en Chile: hacia un enfoque generacional». Última Década N³5. Valparaíso: Ediciones CIDPA. (2004): «Imágenes y estudios cuantitativos en la construcción social de 'la juventud chilena'. Un acercamiento histórico (2003-1967)». Última Década N²0. Valparaíso: Ediciones CIDPA. 
Obando, Claudio (2008): «El (ab)uso del olvido. Terrorismo de Estado y lesión a la memoria colectiva». Actuel Marx Intervenciones $\mathrm{N}^{\circ} 6$. Santiago: LOM.

OliVA, MARÍA ANGÉLICA (2010): «Política educativa chilena 1965-2009. ¿Qué oculta esa trama?». Revista Brasileira de Educação, Vol. 15, №44. Brasil: Associação Nacional de Pós-Graduação e Pesquisa em Educação. (2008): «Política educativa y profundización de la desigualdad en Chile». Revista Estudios Pedagógicos, Vol. 34, №2. Valdivia: Universidad Austral de Chile.

PAREDES, YENNY (2007): Grafiti y ciudad: discursos murales o la elocuencia del silencio. Material de estudio complementario e inédito. Valdivia: Instituto de Linguiística y Literatura, Facultad de Filosofía y Humanidades, Universidad Austral de Chile.

PINO-OJEDA, WALESCKA (2014): «Insurgency of Discourse and Affective Intervention: The Chilean Students' Movement». Argos Aotearoa $\mathrm{N}^{\circ} 1$. Auckland: SG Digital.

PORTILlO, MARICELA et al. (2012): «De la generación X a la generación @ . Trazos transicionales de identidades juveniles en América Latina». Última Década №37. Valparaíso: Ediciones CIDPA.

RAMÍREZ, JUAN (1992): Arte y arquitectura en la época del capitalismo triunfante. Madrid: Visor.

REguillo, Rossana (2000): Emergencia de culturas juveniles. Estrategias del desencanto. Buenos Aires: Grupo Norma.

SANDOVAL, MARIO (2012): «La desconfianza de los jóvenes: sustrato del malestar social». Última Década N³6. Valparaíso: Ediciones CIDPA.

SANDOVAl, AlejANDRA (2001): Palabras escritas en un muro. El caso de la Brigada Chacón. Santiago: Ediciones Sur.

SALAZAR, GABRIEL (2006): La violencia política popular en las grandes Alamedas: la violencia en Chile 1947-1987. Una perspectiva históricopopular. Santiago: LOM.

— y Julio PINTO (1999): Historia contemporánea de Chile. Niñez y juventud. Vol. V. Santiago: LOM.

SALINAS, DANIEL y PABLO FRASER (2012): «Educational Opportunity and Contentious Politics: The 2011 Chilean Student Movement». Berkeley Review of Education, Vol. 3, N¹. Berkeley: University of California.

Silva, Armando (1987): Punto de vista ciudadano. Focalización visual y puesta en escena del graffiti. Bogotá: Caro y Cuervo.

SOMMA, NiCOLÁs (2012): «The Chilean Student Movement of 2011-2012: Challenging the Marketization of Education». Interface: A Journal for and about Social Movements, Vol. 4, №2. Maynooth: National University of Ireland.

TORCHE, FlORENCIA (2005a): «Privatization Reform and Inequality of Educational Opportunity: The Case of Chile». Sociology of Education, Vol. 78, Nº . Washington, DC: American Sociological Association. 
_ (2005b): «Unequal but Fluid: Social Mobility in Chile in Comparative Perspective». American Sociological Review, Vol. 70, №3. Washington, DC: American Sociological Association.

VAlenZuela, EduARDo (1984): La rebelión de los jóvenes. Santiago: Sur Ediciones.

VAN DiJK, Teun (2012): Discurso y contexto. Barcelona: Gedisa.

- (2010): «Political Identities in Parliamentary Debates». En I. Cornelia (Ed.): European Parliaments under Scrutiny. Discourse Strategies and Interaction Practices. Amsterdam: Benjamins.

— (2009): Discurso y poder. Barcelona: Gedisa.

_ (2008): «Semántica del discurso e ideología». Revista Discurso y Sociedad, Vol. 2, $\mathrm{N}^{\circ} 1$.

- (2003): «La multidisciplinaridad del análisis crítico del discurso: un alegato en favor de la diversidad». En R. WODAK y M. MEYER (coordinadores): Métodos de análisis crítico del discurso. Barcelona: Gedisa.

- (2001): «Algunos principios de una teoría del contexto». Revista Latinoamericana de Estudios del Discurso, Vol. 1, Nº1. Bogotá: ALED.

— (2000): «El discurso como interacción en la sociedad». En T. VAN DIJK (compilador): El discurso como interacción social. Estudios del discurso: introducción multidisciplinaria, Vol.2. Barcelona: Gedisa. (1999): Ideología. Barcelona: Gedisa.

— (1996): «Análisis del discurso ideológico». Revista Versión. Estudios de Comunicación y Política $\mathrm{N}^{\circ} 6$. Xochimilco: Universidad Autónoma Metropolitana.

WODAK, RUTH (2003): «De qué trata el análisis crítico del discurso (ACD). Resumen de su historia, sus conceptos fundamentales y sus desarrollos». En R. WODAK y M. MEYER (coordinadores): Métodos de análisis crítico del discurso. Barcelona: Gedisa. 